\title{
25 VIEWING INFORMATION TECHNOLOGY OUTSOURCING ORGANIZATIONS THROUGH A POSTCOLONIAL LENS
}

\author{
Ravishankar Mayasandra \\ The Business School \\ Loughborough University \\ Leicestershire, UK \\ Shan L. Pan \\ School of Computing \\ National University of Singapore \\ Singapore \\ Michael D. Myers \\ Information Systems and Operations Management \\ University of Auckland \\ Auckland, New Zealand
}

\begin{abstract}
This paper discusses some of the difficulties and challenges that an information technology (IT) firm in a developing country faces in its attempt to become a global player. In 1999, the firm KnowICT embarked on a strategic project called Knowledge Management (KM), whose main purpose was to unify and integrate knowledge that resided in the various organizational business units into one strategic knowledge infrastructure. By combining the knowledge resources dispersed in the various organizational business units, KnowICT managers hoped that KnowICT could be transformed into a leading global IT consultancy firm, rather than be seen just as a provider of routine outsourcing jobs. Although at a basic operational level the KM project has been deemed a success, the attempt to combine the knowledge resources from the various organizational business units proved more difficult than anticipated. We use postcolonial theory to explain the difficulties and
\end{abstract}

Please use the following format when citing this chapter:

Mayasandra, R., Pan, S.L., and Myers, M.D., 2006, in IFIP International Federation for Information Processing, Volume 208, Social Inclusion: Societal and Organizational Implications for Information Systems, eds. Trauth, E., Howcroft, D., Butler, T., Fitzgerald, B., DeGross, J., (Boston: Springer), pp. 381-396. 
challenges that KnowICT faces. Postcolonial theory draws attention to issues of power, ownership, control, and identity. We suggest postcolonial theory can meaningfully enhance our understanding of the development and use of information and communication technologies in developing countries.

\section{INTRODUCTION}

The benefits and costs of outsourcing information technology services to developing countries such as India have been discussed quite extensively in the literature, with the promise of lower costs being one of the key drivers (DiRomualdo and Gurbaxani 1998; Earl 1996; Lacity and Hirschheim 1993; McFarlan and Nolan 1995). One notable feature of the research literature on global outsourcing, however, is that most authors discuss outsourcing only from the perspective of the organization that is seeking to outsource part of its business. That is, the benefits, costs, and risks of outsourcing have been considered mostly in relation to the concerns of organizations in the developed world. Almost all of the published case studies of outsourcing are from first world countries (e.g., Baldwin et al. 2001; Lacity and Willcocks 1998; Zviran et al. 2001). There have been a few exceptions in recent years with researchers drawing on theoretical lenses such as organizational politics, culture, and power (Heeks et al. 2001; Nicholson and Sahay 2001) to highlight important issues in the interactions between vendor organizations in the third world and their global clients. Also, in 2003, a special issue of The Electronic Journal of Information Systems in Developimg Countries was devoted to the growth of the IT software export industry in developing countries. However, on the whole, much less is known from the perspective of the outsourcing vendors (i.e., organizations that offer IT outsourcing services) in developing countries. The benefits, costs and risks of outsourcing for organizations in developing countries seem to have been largely ignored. One of the contributions of this paper is that it explicitly considers outsourcing from the other side of the fence (i.e., from the perspective of KnowICT, ${ }^{\prime}$ one of the largest outsourcing vendors in India).

The main contribution of this paper is its application of postcolonial theory to the development and use of information and communication technologies (ICT) in developing countries. In doing so, it draws mainly from the application of this theory to one specific project at KnowICT called Knowledge Management (KM) whose purpose was to unify and integrate knowledge that resided in the various business units into one strategic knowledge infrastructure. This paper is organized as follows. The next section discusses postcolonial theory. The following section discusses the research method. Next, the case of the KM project within KnowICT is discussed, followed by an analysis and discussion of the KM project in the light of postcolonial theory and conclusion.

\footnotetext{
${ }^{1}$ KnowICT is a pseudonym.
} 


\section{THEORETICAL BACKGROUND}

Most of the studies on the topic of ICT in developing countries focus on the issue of their impact and use on economic development or public administration (Avgerou 1990; Bhatnagar 2000; Fleming 2002). A few others focus on cross-cultural issues especially in relation to the subject of globalization (Gallupe and Tan 1999; Ives and Jarvenpaa 1991). In the latter category, Walsham $(2001,2002)$ discusses what globalization means in particular situations and contexts. He says that, for some, globalization and the spread of ICT throughout the world means the increasing homogenization of culture. For others, globalization is interpreted as a process whereby imported ideas, concepts, and artefacts are "indigenized."

While we agree wholeheartedly that cross-cultural issues are very important in attempting to understand the role of ICT in developing countries, the main contribution of postcolonial theory is that it enables us to see ICT developments in the developing countries in a much broader context-the long-standing historical relationship of colonialism, neocolonialism, and postcolonialism of the West to the developing world (Adam and Myers 2003). Loomba (1998, p. 2) defines the word colonialism as "The conquest and control of other people's land and goods," for example, British colonialism. Colonialism describes a system of political, economic, and social dominance over the colony by another country (Adam and Myers 2003).

\subsection{Postcolonialism}

Young (2001) says that postcolonialism can be defined as coming after colonialism and imperialism, in their original meaning of direct-rule domination. The postcolonial "marks the broad historical facts of decolonization and the determined achievement of sovereignty - but also the realities of nations and peoples emerging into a new imperialistic context of economic and sometimes political domination" (Young 2001, p.57). Loomba suggests that a country may be both postcolonial (in the sense of being formally independent) and neocolonial (in the sense of remaining economically and/or culturally dependent) at the same time. She says that postcolonialism is a word that is useful only if we use it with caution and qualifications. Postcolonial is a descriptive not an evaluative term, a point further emphasized by Prasad (2003, p. 7), who suggests that when using postcolonial theory or postcolonialism it should be noted that "Postcolonialism is not a narrowly systematized and unitary theory. Rather, postcolonial theory is a set of productively syncretic theoretical and political positions that creatively employ concepts and epistemological perspectives deriving from a range of scholarly studies."

According to Quayson (2000, p. 2), "A possible working definition for postcolonialism is that it involves a studied engagement with the experience of colonialism and its past and present effects, both at the local level of ex-colonial societies as well as at the level of more general global developments thought to be the after-effects of empire." Ashcroft (2001) focuses on the response of the colonized to the political and cultural dominance of Europe. In his view, the term postcolonial refers to all culture 
affected by the imperial process from the moment of colonization to the present day. "Post-colonial discourse is the discourse of the colonized, which begins with colonization and doesn't stop when the colonizers go home" (p. 12). Ashcroft argues that postcolonial theory is particularly relevant to the subject of globalization. He says "we cannot understand globalization without understanding the structure of global power relations which flourishes in the twenty-first century as an economic, cultural and political legacy of Western imperialism" (p. 208). In other words, although the term postcolonialism suggests an engagement purely with the original European colonial powers, as a theory, postcolonialism includes in its ambit discussions of the engagement of the once colonized with most of the developed world, including both North America and Europe. We agree with Ashcroft's assessment and suggest that postcolonial theory is a useful device for understanding globalization and the role of ICT in developing countries.

\subsection{Postcolonial Theory and India}

Postcolonial theory is particularly relevant to India. For close to 200 years, India was ruled as a British colony. The direct and indirect impacts of colonialism on India continue to be an area of scholarly interest and it is widely acknowledged that postcolonial theory offers important insights into the social, cultural, political, and industrial developments in the country over the last few decades of independent rule (Cohn 1996; Dirks 2001). Generally speaking, there are two distinct perspectives on colonialism and its impacts on India. The first and more traditional set of arguments focus on the excesses of colonial rule and its deleterious effects on the people and society at large. The reasoning behind this focus is well expressed by Raychaudhari (1999, p. 157), who writes, "It is difficult for the citizens of a former dependency which has gone through a prolonged struggle for independence to acknowledge any benefits of colonial rule." Some scholars have noted that the colonizers cleverly appropriated the understanding of local languages, customs, and traditions at which they arrived in order to impose a stronger colonial rule (Cohn 1996; Dirks 2001). The second perspective of colonialism in India, while acknowledging the negative aspects of colonialism, notes that it also had a positive impact insofar that it mobilized disparate constituencies to come together, giving the nation itself an identity. As Khilnani (1997, p. 21) writes,

Foreign rulers brought with them to India a concept of the state-with its distinct, if often locally influenced, administrative and military technologies, its claim to rule over a precise territory, its determination to initiate social reforms, and its reorganization of the texture of the community-that drastically changed ideas about power in India.

Over the last decade and a half, the postcolonial era has seen the creation of a number of private enterprises in India, many of which have emerged as highly competitive players in the global market. These enterprises were mostly formed by entrepreneurs who wished to operate globally and overcome the effects of what some scholars refer 
to as subtle forms of postcolonialism or neocolonialism. KnowICT is one such company.

In short, it appears to us that postcolonial theory is particularly relevant to the study of globalization and the role of ICT in developing countries. We suggest that the contemporary phenomenon of IT outsourcing is yet the latest incarnation of the (post)colonial encounter, and hence, postcolonial theory or postcolonialism has much to offer in helping us to understand this global phenomenon. Postcolonial theory draws attention to issues of power, ownership, control, and identity, issues that were central to the particular information system project discussed in this paper.

\section{RESEARCH METHODS}

The research method used was that of interpretive case study (Klein and Myers 1999). One of the authors conducted intensive fieldwork at KnowICT Technologies in three phases, for a total period of 8 months. Multiple qualitative data sources were used including documents, e-mails, the Internet, field notes, and $\mathrm{KM}$ artifacts. One of the main sources of data was 52 in-depth interviews with informants from various business units including middle level managers, top management, and software developers. All of the interviews were conducted at the headquarters of KnowICT in India. Each interview lasted on an average about 90 minutes. All of the interviews were audio taped with prior permission and then transcribed. All of the interviews were direct face-to-face interactions, while follow-up discussions were conducted via telephone and/or e-mail.

At the end of the first two phases of data collection, we invited a member of the top management at KnowICT to visit the National University of Singapore (at the time, the location of both the first and second authors). We discussed and clarified with him our preliminary understanding of the case and the ideas we had formulated thus far. At the end of the two phases of field-work, we had acquired vast amounts of both primary and secondary empirical material, in the analysis of which we followed broadly the approaches outlined in Walsham and Sahay (1999). Interview threads that appeared particularly engaging and fruitful were highlighted during a long, drawn-out initial cyclic process of listening to the audio tapes, transcribing, and re-listening. This was followed by an open coding process involving a line-by-line analysis of all of the interview transcripts and the field-notes (Strauss and Corbin 1998). The open coding process in tandem with the highlighted interview threads and field-notes led to the identification and inductive placement of the main emerging issues into conceptual categories. Periodically throughout this process, we read and discussed a number of times the interview transcripts and the detailed notes made during field work in order to develop a better understanding of the various categories. Once the relationships between the categories became clearer, they were combined with the available secondary data to produce a written draft describing the case. The three authors then engaged the empirical material in an iterative interaction with the theoretical formulations underpinning the study leading to the theoretically abstracted discussion and conclusion sections. 


\section{CASE DESCRIPTION}

KnowICT is one of the largest IT companies in India. KnowICT serves more than 450 global clients, has more than 35 software development centers and sales offices world-wide, and employs more than 45,000 people. KnowICT offers IT services, IT products, and consulting services that cut across a diverse range of industry segments such as manufacturing, retail, energy, financial services, health care, and telecommunications. KnowICT was founded in the early 1980 s with a vision of creating a world-class organization. The founders had come around to the view that the answers to the major issues facing India such as unemployment, poverty, bad living conditions, and lack of accountability, to name a few, were not to be found in the "inward" looking models of economic development. Rather, they came to believe that only by creating a strong and independent profit-oriented organization that engaged in trade globally could a contribution be made toward improving the lot of the country's growing population. They believed that, indirectly at least, the benefits of running a globally profitable and successful organization would percolate down to the people and the society as a whole.

\subsection{Initial Hurdles}

In the $1980 \mathrm{~s}$, Indian government agencies controlled the availability and movement of even basic resources that were required to run entrepreneurial private companies. The bureaucratic functioning of these governmental agencies presented numerous hurdles for companies like KnowICT. For example, importing computers from abroad was a long process that necessitated the approval of a host of government departments, sometimes taking years. However, things started looking up for KnowICT in 1991, with the Indian government relaxing some of its earlier regulations. Foreign companies were allowed to invest freely in indigenous companies, multinational companies were allowed to set up offices in India, licensing restrictions on import of technology goods were removed, and the role of the government in the initial public offering process of all companies was minimized. KnowICT grew rapidly throughout the $1990 \mathrm{~s}$. During this period, KnowICT moved away from doing short-term, one-off projects to handling more complex software development, maintenance, testing, and package implementation projects.

\subsection{The Knowledge Management (KM) Project}

In late 1999, KnowICT embarked on a strategic project called Knowledge Management (KM). A KM implementation team (or KM group) was created in conjunction with the organization's research and training department. The main purpose of the project was to unify and integrate knowledge that resided in the various business units into one strategic knowledge infrastructure. By combining the knowledge resources dispersed in the various organizational business units, KnowICT managers hoped that KnowICT could take big steps toward transforming itself into a truly global firm. 
The top management team sensed from their interactions with clients that they expected a lot more from KnowICT. Rather than KnowICT throwing a solution across the wall in response to the customer throwing across a requirement, it appeared that the customers now expected KnowICT to anticipate their business requirements and come out with solutions that added strategic value. The top management team, therefore, wanted to initiate a project to effectively harness the knowledge dispersed and embedded in the various business units, thereby enabling KnowICT to be a step ahead of customers and in a position to offer "strategic IT solutions." Another reason for the KM project was to create a stronger KnowICT identity amongst KnowICT employees. This started to be seen as a problem given the rapid growth of KnowICT as a company. In 1997, less than 2,000 people worked for KnowICT, but by 1999, there were close to 20,000 KnowICTians dispersed throughout the organization in various parts of the world. Most of these employees tended to work closely with various client organizations, and so their sense of affiliation with KnowICT was not as strong as it could be. The KM challenge was thus to ensure that employees and business units working for important global clients also strengthened the knowledge resources of KnowICT. The former head of the KM group under whose stewardship the KM project was launched explained:

With the business model we follow, the notion of belonging to a single organizational entity is not as strong as compared to other industries. Typically, the technologies that we work on are not proprietary to KnowICT and, therefore, the extent to which KnowICTians tap into organizational resources for their learning and troubleshooting needs is minimal. Therefore, we felt that the organizational apparatus that people access needed further strengthening.

The KM project gained increased visibility and a common platform with the introduction of a central KM portal. Knowledge Market (KMarket), the internally developed knowledge portal, was rolled out in early 2000; it now represents the platform for KnowICT's KM project. With the launch of the central KM portal, a nine-member team called the central KM group was formed to drive the organization-wide KM project. The KM group is a blend of senior project managers, software engineers, research analysts, and marketing managers. The organization-wide KM project mainly revolves around voluntary submission of documents (also called knowledge assets) to KMarket, and the subsequent use of these assets by other KnowICTians.

\section{ANALYZING THE CHALLENGES}

Although at a basic operational level the KM project has been deemed a success, KnowlCT currently faces a few important challenges. The heavily decentralized structure of KnowICT and the exclusive long-term relationships with client organizations pose interesting questions to the KM implementation team and the organization. The challenges posed by the organizational structure will be considered first. 


\subsection{Organizational Restructuring}

The decentralized structure of KnowICT and long-term relationships with client organizations pose interesting challenges to the KM implementation team and the organization. KnowICT has recently restructured itself into a number of decentralized business units (DBU), which function as independent profit-centers. The DBU-based organization structure is a more decentralized version of the earlier organizational structure and aims at empowering each strategic unit to differentiate itself from the others. To some extent the movement toward greater decentralization, specifically the DBUbased structure, which encourages each business unit to differentiate itself from other DBUs, has moved KnowICT further away from the KM vision of having a centralized knowledge apparatus. At the same time, however, it has meant that the KM project is seen as being needed more now than ever.

\subsection{Knowledge Ownership}

Exclusive long-term relationships with client organizations pose more fundamental challenges to the KM project. To illustrate the key problem of knowledge ownership, we will analyze the case of one DBU in particular, KnowICT-1, a business unit that caters to global clients belonging to a particular industry segment. KnowICT-1 has steadfastly focused on this industry segment over the last 10 years and, apart from a few renaming exercises and minor realignments during organizational restructuring, has retained its essential structure throughout this period. Rather than participating in oneoff projects, KnowICT-1 plays a bigger role in the functioning of the client organization, a strategically beneficial situation for KnowICT. KnowICT-1 has dedicated development centers to serve its clients and the teams typically handle projects involving the design, development, and testing of software vital for the customers' operations. A few project teams at KnowICT-1 are also involved in the long-term maintenance and troubleshooting of the customer IT infrastructure. At present, KnowICT-1 employs about 1,500 KnowICTians who work on various projects. A notable feature of KnowICT-1's clients is that they come from the same industry segment, and they compete with one another in the global market. This means that KnowICT-1 employees who do work for Company A are unable to share information with other KnowICT-1 employees who might be working for Company B. This inability to share knowledge was explained by a senior software engineer as follows:

Organization-wide management of knowledge is a strict no-no here. We [KnowICT-1] serve mutually competing firms and each firm is very strict about guarding its intellectual property rights. Even innocent exchange of information and benevolent use of shared knowledge with the rest of the organization may infringe upon the IP of another client. So I am afraid we don' $t$-are not allowed to really share anything useful with the rest of the organization. 
KnowICT has signed explicit nondisclosure agreements with all the client organizations that KnowICT-1 serves. A senior project manager explained that the nondisclosure agreements with the client organizations were worded very carefully. Taking the case of KnowICT-1's three main client organizations, Xena, Rena, and Cena, ${ }^{2}$ he explains:

Our agreements have more to it than just safeguards against explicit knowledge transfer. The agreement with Xena for example, very clearly states that members of KnowICT-I working for Xena cannot be relocated to any KnowICT-1 team that works for Rena or Cena, unless they have spent a year in-between at some other KnowICT unit. We also have clauses that protect KnowICT against possible poaching by client organizations. None of our client organizations can directly absorb any KnowICT employee into their organizations, except in cases where the employee has left KnowICT and has worked elsewhere at least for a year.

The elaborate and stringent agreements with the client organizations at KnowICT-1 in effect prevent knowledge sharing within KnowICT-1, let alone knowledge sharing across the whole KnowICT organization. A project team leader at KnowICT-1 believed that the participation of KnowICT-1 in the organization-wide KM project could be counterproductive to the client organization:

The projects that we work on at our development centers at KnowICT-1 involve design and development of software for clients' infrastructure. And with KMarket or organization-wide KM, there is a good chance that a few designs, feature implementations, processes, practices etc, [could] find their way out to places where the client may not want it to. Besides, some of our project managers hold key business and market information about the client organization's current and future software releases...safeguarding such information is critical from the client's perspective.

A senior software engineer explained:

I have realized that in the first place, our clients are very particular about the nature of work they outsource to us. They meticulously scrutinize each and every single detail of the coding we are required to do to make sure that we are handling less strategic aspects. So it's not as if we are working on big ideas and innovations that carry a great risk if shared. Having said that, I feel the knowledge sharing restrictions have made it difficult for others at KnowICT to tap into our expertise. Basically all this shows who has the control!

${ }^{2}$ The names of the client organizations have been disguised to protect their identities. 
For the client organizations outsourcing to KnowICT, it is imperative that the dedicated KnowICT project teams working for them function purely as offshore extensions of the client facility. Managing and sharing knowledge for the clients is an important issue as long as it is within the KnowICT project teams that are working for them, and as long as such knowledge sharing favors the client organizations. According to a senior software engineer at KnowICT-1, client organizations tend to be very committed to the implementation of KM practices, but only when these are within the boundaries of the project teams working for them. We observe that KnowICT-1 appears to remain separate or is isolated from KnowICT and the organization-wide KM project at two levels: at a technology level and at a subcultural level.

\subsection{Technology-Based Separation}

Responding to the client organizations' requirement for knowledge hoarding within the KnowICT-1 project teams (and explicit restrictions on knowledge sharing outside of those teams), KnowICT-1 requires its project teams to remain suitably isolated from the organizational mainstream. Therefore, the IT infrastructure at the various KnowICT1 development centers is cordoned off from the rest of the organization using firewalls. As a result of this fire walling, the servers and workstations within KnowICT-1 cannot be accessed from the rest of the organization. Any access to the servers located within KnowICT-1 from outside is possible only through access authentication, which is available to a select few in the organizational hierarchy.

\subsection{Subcultural Separation from the Organizational KM Project}

As KnowICT moves ahead with its decentralization-focused organizational structure, and emphasizes long-term project assignments, the organization-wide KM project also runs into deeply entrenched subcultural patterns within its business units. Employees who have worked for a specific customer for a long time are guided in their actions by their frequent interaction with the client and identify with the client organization more than they do with KnowICT. A software engineer from business unit KnowICT-2 and part of a team that serves a manufacturing company said:

To me any process that the organization emphasizes is an overhead and I consider KM to be an overhead. But if the same process is mandated as a requirement by the client organization, then I would definitely take part in it. It's just the way we have come up, we are ready to do anything for the client. But even though we know that we also have to contribute to the KM project at the organizational level, somehow we don't seem to do that.

The client organizations consider their respective offshore KnowICT teams as part of their global operations. Conversely, the KnowICT project team members see 
themselves as almost a part of the client organization. The strong identification with the client means that many project team members do not see much benefit in creating an integrated central knowledge apparatus for KnowICT as a whole.

\section{DISCUSSION}

We will now proceed to discuss the KM project at KnowICT in the light of postcolonial theory. Gardner and Lewis $(1996$, p. 2) note that,

while it is certainly important to analyze the structures which perpetuate underdevelopment, we must also recognize the ways in which individuals and societies strategize to maximize opportunities, how they resist structures which subordinate them and, in some cases, how they successfully embrace capitalist development.

This is exactly what we have attempted to do in telling the story of the KM project at KnowICT. KnowICT executives have strategized to maximize their opportunities and, by and large, they have been remarkably successful. They have successfully embraced capitalist development and KnowICT has emerged as one of the largest IT firms in India.

Ashcroft (2001) says that the most contentious problems in postcolonial theory continue to be those hinging on the capacity of the colonized subjects to intervene in colonial discourse to contest it, change it, or generally make the voice of the colonized heard. He says that "the colonial subject may engage imperial culture by using it as a communicative medium or consuming it as cultural capital" (p. 45). To this particular point of Ashcroft's, we would add that the phenomenon of global outsourcing takes this one step further. KnowICT does not just use and/or consume Western or imperial knowledge and culture; rather, KnowICT actually produces it. KnowICT produces software applications, technology, and knowledge for companies in the developed world. But the paradox is that KnowICT does not own much of the knowledge or technology it produces. Loomba (1998) points out that colonialist knowledge was produced via negotiation with or an incorporation of indigenous ideas: "At a very practical level, colonialists were dependent upon natives for their access to the 'new' lands and their secrets" (p. 67). In a similar way, large companies in the developed world have become dependent upon KnowICT for the development of new software applications, maintenance services, implementation of new technologies, and network management. In the light of postcolonial theory, the global outsourcing phenomenon can be seen as a postcolonial extension of the appropriation or incorporation of indigenous ideas. One important difference from the colonial area, of course, is that KnowICT's role is to produce new software and new knowledge, not traditional indigenous knowledge. However, the outcome is still the same: the goods and resources that are produced are owned by companies in the developed world, not KnowICT. The intellectual property belongs entirely to client organizations such as IBM or Microsoft. 
The problems of agency referred to earlier by Ashcroft--the extent the colonized can "intervene"- are central to the case of the KM project at KnowICT. On the one hand, KnowICT managers realized that "knowledge is power" - and they wanted more knowledge concentrated within their own company. The KM project at KnowICT was explicitly designed to unify and integrate knowledge that resided in the various business units into one strategic knowledge infrastructure. However, the KM project failed in its strategic objective to unify and integrate knowledge within the company. One of the main reasons for its failure was the nondisclosure agreements with clients. As it is the large companies in the developed world (the clients of KnowICT) that pay for the outsourcing work to be done, they are the ones that retain all of the intellectual property rights. Loomba says that "knowledge is not innocent but profoundly connected with the operation of power" (p. 43). In this particular case, then, KnowICT remained as "powerless" as before. It did not gain ownership of or even access to the knowledge it produces. The knowledge that it produced remained firmly locked up within the firewalled enclosures of its business units.

On the other hand, we have seen that KnowICT managers and employees do not lack agency. For example, KnowICT executives restructured the company into decentralized business units; they themselves took this initiative, and no one forced them to do so. While this restructuring was done for sound business reasons, it had the effect of strengthening the independence and identity of each DBU at the expense of KnowICT as a whole. It moved KnowICT further away from the goal of having a shared KnowICT identity, which brings us to the issue of identity, an important concept in postcolonial theory. Like the issues of ownership and control, the issue of identity is central to understanding the failure of the $\mathrm{KM}$ project. An interesting feature of KnowICT is that many of its employees identify as much if not more with the client than they do with their own company. One reason is that KnowICT likes to have long-term relationships with its clients. Teams within KnowICT tend to be separated technologically and subculturally from each other. In a sense, this separation is a postcolonial variant of the British strategy of "divide and rule"-although, of course, this effect today is largely unintended by KnowICT's clients. Further, the strong identification with the client and the culture of knowledge sharing within teams meant that most KnowICT employees within the DBU had little interest in contributing to the organization-wide KM project. Our research reveals that the KM project was effectively doomed from the start (or at least it was doomed with respect to the achievement of its strategic objectives).

Finally, we note that it is important to compare KnowICT's case with other IT organizations (e.g., organizations operating in developed countries and global organizations having operations in developing countries) that face similar issues of knowledge ownership and confidentiality with client organizations. At first glance, the presence of similar issues in these other IT organizations suggests that these are simply indicators of tensions in all client-vendor relationships, rather than unique expressions of postcolonial asymmetries in KnowICT's case. However, we argue that a closer examination of issues of power and control at the industry and governmental levels would still reveal that indigenous firms in developing countries are heavily constrained by their inability to intervene meaningfully in comparison with other IT organizations when 
furthering their global aspirations. In this paper, we have suggested that such constraints faced by indigenous organizations, in addition to being manifestations of organizational issues can also be viewed in the much larger context of postcolonialism. Further empirical work is required to investigate in greater detail the issues raised here.

\section{CONCLUSION}

KnowICT has been tremendously successful in the postcolonial era in India by offering outsourcing services to global clients in the developed world. However, it faces numerous challenges as it seeks to move away from routine outsourcing jobs and transform itself into a leading global IT consultancy firm. These challenges are vitally concerned with issues of power, ownership, control, and identity. We have suggested that postcolonial theory offers a useful perspective from which to understand the difficulties and challenges that KnowICT faces. It enables us to look at the development and use of ICT in developing countries within a broad context. From the perspective of postcolonial theory, the global outsourcing phenomenon can be seen as but the latest incarnation of colonialism. KnowICT produces knowledge, technology, and systems for clients in the developed world, but it does not own it. The lack of ownership and control over knowledge was brought into sharp relief by the KM project that was started in 1999. Although the main purpose of this project was to unify and integrate knowledge that resided in the various business units into one strategic knowledge infrastructure, the goal was never achieved. Intellectual property agreements with clients, the technology and subcultural separation of teams from one another, and a closer identification of KnowICT employees with the client organizations meant that any meaningful knowledge sharing was impossible.

One possible limitation of our study is the perspective of knowledge that we have taken in discussing the KM project. While we have viewed knowledge mostly as a commodity that the vendor organization gains or loses, taking a practice perspective of knowledge as some organization theorists have done (e.g., Blackler 1995) would require us to question the exact nature of organizational knowledge being gained or lost by the vendor. In conclusion, although KnowICT was started in response to the perceived postcolonial handicaps of India as a developing country, the company remains dependent upon companies in the developed world, albeit in a more subtle and sophisticated way. How KnowICT moves ahead from routine outsourcing and transforms itself into a leading IT consulting firm remains to be seen.

\section{References}

Adam, M. S., and Myers, M. D. "Have You Got Anything to Declare? Neo-colonialism, Information Systems, and the Imposition of Customs and Duties in a Third World Country," in M. Korpela, R. Montealegre, and A. Poulymenakou (eds.), IS Perspectives and Challenges in the Context of Globalization, Boston: Kluwer Academic Publishers, 2003, pp. 101-115. 
Ashcroft, B. Post-Colonial Transformation, London: Routledge, 2001.

Avgerou, C. "Computer-Based Information Systems and Modernisation of Public Administration in Developing Countries," in S. C. Bhatnagar and N. Bjørn-Andersen (eds.), Information Technology in Developing Countries, Amsterdam: Elsevier Science Publishers, 1990, pp. 243-250.

Baldwin, L. P., Irani, Z., and Love, P. E. "Outsourcing Information Systems: Drawing Lessons from a Banking Case Study," European Journal of Information Systems (10:1), 2001, pp. $15-24$.

Bhatnagar, S. "Social Implications of Information and Communication Technology in Developing Countries: Lessons from Asian Success Stories," Electronic Journal on Information Systems in Developing Countries (1:4), 2000, pp. 1-10.

Blackler, F. "Knowledge, Knowledge Work and Organizations: An Overview and Interpretation," Organization Studies (16:6), 1995, pp. 1020-1042.

Cohn, B. S. Colonialism and its Forms of Knowledge, Princeton, NJ: Princeton University Press, 1996.

Dirks, N. B. Castes of Mind: Colonialism and the Making of Modern India, Princeton, NJ: Princeton University Press, 2001.

DiRomualdo, A., and Gurbaxani, V. "Strategic Intent for IT Outsourcing," Sloan Management Review (39:4), 1998, pp. 67-80.

Earl, M. J. "The Risks of Outsourcing IT," Sloan Management Review (37:3), 1996, pp. 26-32.

Fleming, S. "Information and Communication Technologies (ICTs) and Democracy Development in the South: Potential and Current Reality," Electronic Journal on Information Systems in Developing Countries (10:3), 2002, pp. 1-10.

Gardner, K., and Lewis, D. Anthropology, Development and the Post-Modern Challenge, Chicago: Pluto Press, 1996.

Gallupe, R. B., and Tan, F. B. "A Research Manifesto for Global Information Management," Journal of Global Information Management (7:3), 1999, pp. 5-18.

Heeks, R., Krishna, S., Nicholson, B., and Sahay, S. "Synching or Sinking: Global Software Outsourcing Relationships," IEEE Software (18:2), 2001, pp. 54-60.

Ives, B., and Jarvenpaa, S. L. "Applications of Global Information Technology: Key Issues for Management," MIS Quarterly (15:1), 1991, pp. 32-49.

Khilnani, S. The Idea of India, London: Hamish Hamilton, 1997.

Klein, H. K., and Myers, M. D. "A Set of Principles for Conducting and Evaluating Interpretive Field Studies in Information Systems," MIS Quarterly (23:1), 1999, pp. 67-93.

Lacity, M. C., and Hirschheim, R. "The Information Systems Outsourcing Bandwagon," Sloan Management Review (35:1), 1993, pp. 73-86.

Lacity, M. C., and Willcocks, L. P. "An Empirical Investigation of Information Technology Sourcing Practices: Lessons from Experience," MIS Quarterly (22:3), 1998, pp. 363-408.

Loomba, A. Colonialism/Postcolonialism, London: Routledge, 1998.

McFarlan, F. W., and Nolan, R. L. "How to Manage an IT Outsourcing Alliance," Sloan Management Review (36:2), 1995, pp. 9-23.

Nicholson, B., and Sahay, S. "Some Political and Cultural Issues in the Globalization of Software Development: Case Experience from Britain and India," Information and Organization (11:1), 2001, pp. 25-43.

Prasad, A. (ed.). Postcolonial Theory and Organizational Analysis: A Critical Engagement, New York: Palgrave Macmillan, 2003.

Quayson, A. Postcolonialism: Theory, Practice or Process?, Cambridge, UK: Polity Press, 2000 
Raychaudhuri, T. Perceptions, Emotions, Sensibilities, Oxford, UK: Oxford University Press, 1999.

Strauss, A., and Corbin, J. Basics of Qualitative Research, Thousand Oaks, CA: Sage Publications, 1998.

Walsham, G. "Cross-Cultural Software Production and Use: A Structurational Analysis," MIS Quarterly (26:3), 2002, pp. 359-380.

Walsham, G. Making a World of Difference: IT in a Global Context, Chichester: Wiley, 2001.

Walsham, G., and Sahay, S. "GIS for District-Level Administration in India: Problems and Opportunities," MIS Quarterly (23:1) 1999, pp. 39-65.

Young, R. J. C. Postcolonialsm: An Historical Introduction, Oxford, UK: Blackwell Publishers, 2001.

Zviran, M., Ahituv, N., and Armoni, A. "Building Outsourcing Relationships Across the Global Community: The UPS-Motorola Experience," Journal of Strategic Information Systems (10:4), 2001, pp. 313-333.

\section{About the Authors}

Ravishankar Mayasandra is a lecturer in Strategy and part of the International Business and Strategy (IBS) research group at The Business School, Loughborough University, UK. He completed his doctoral research at the Department of Information Systems, School of Computing, National University of Singapore, in 2005. Earlier, he received his Bachelor of Engineering degree in Electronics and Communication Engineering (1999) from Bangalore University, India, and spent close to two years in a business development position at an India-based IT start-up firm. His current research interests include strategic global IT outsourcing, IT in developing nations, KM solutions for the business process outsourcing (BPO) industry, and issues of identity in large organizations. Typically, in conducting and presenting his research, Ravi adopts qualitative research methods such as case studies and ethnographies. Ravi can be reached by e-mail at M.N.Ravishankar@lboro.ac.uk

Shan L Pan is an assistant professor and the coordinator of Knowledge Management Laboratory in the Department of Information Systems, School of Computing at the National University of Singapore. Shan has research interests in the socio-organizational processes that underlie the interaction between information systems and their human and organizational contexts. His primary research focuses on the recursive interaction of organizations and information communication and technology, with particular emphasis on organizational issues such as work practices, cultures, structures, decision-making, change, and strategy implementation that often require qualitative research methods. His research work has been published in MIS Quarterly Executive, IEEE Transaction on Engineering Management, Journal of the American Society for Information Systems and Technology, IEEE Transactions on Systems, Man, and Cybernetics, IEEE Transactions on Information Technology in Biomedicine, European Journal of Operational Research, Communications of ACM, Information and Organization, Journal of Strategic Information Systems, Journal of Organizational Computing and Electronic Commerce, European Journal of Information Systems, Decision Support Systems, and DATA BASE for Advances in Information Systems. Shan can be reached by e-mail at pansl@comp.nus.edu.sg.

Michael D. Myers is Professor of Information Systems and Associate Dean (Postgraduate and Research) at the University of Auckland Business School, New Zealand. He currently serves as Editor in Chief of the University of Auckland Business Review and Editor of the ISWorld Section on Qualitative Research. He previously served as Senior Editor of MIS Quarterly from 
2001-2005, as Associate Editor of Information Systems Research from 2000-2005, and as Associate Editor of Information Systems Journal from 1995-2000. His research articles have been published in many journals and books. He won the Best Paper award (with Heinz Klein) for the most outstanding paper published in MIS Quarterly in 1999. He also won the Best Paper Award (with Lynda Harvey) for the best paper published in Information Technology \& People in 1997. He currently serves as the President-Elect of the Association for Information Systems (AIS) and as Chair of the International Federation of Information Processing (IFIP) Working Group 8.2. Michael can be reached at m.myers@auckland.ac.nz. 